\title{
A prospective study of risk factors for cardiovascular events among the elderly
}

\author{
Marcos Aparecido Sarria \\ Cabrera' \\ Selma Maffei de Andrade ${ }^{2}$ \\ Arthur Eumann Mesas ${ }^{2}$ \\ 'Discipline of Geriatrics, Postgraduate \\ Program in Public Health, \\ ${ }^{2}$ Department of Public Health, \\ Postgraduate Program in Public \\ Health, Universidade Estadual de \\ Londrina, Paraná, Brazil
}

Correspondence: Marcos AS Cabrera Rua Montese 65-A, Londrina, Paraná, Brazil, CEP 860I 5020

Tel +55 4333243524

Fax +55 4333243524

Email marcoscabrera@uol.com.br
This article was published in the following Dove Press journal:

Clinical Interventions in Aging

31 October 2012

Number of times this article has been viewed

Objective: To analyze the impact of cardiovascular (CV) risk factors on the occurrence of fatal and non-fatal CV events in elderly individuals.

Methods: The present research was a prospective cohort study of 800 elderly Brazilian outpatients (60 to 85 years old) with a 12-year follow-up period (baseline: 1997-1998). The outcome variable was CV mortality or non-fatal CV events (stroke, infarction, angina, heart failure). Hypertension, diabetes, global and abdominal obesity, dyslipidemias, and metabolic syndrome were analyzed as independent variables. The analyses were based on Cox proportional hazard models and adjusted for gender, age range, smoking, regular physical activity, and previous cardiovascular disease.

Results: A total of 233 fatal and non-fatal CV events were observed (29.1\%). In the adjusted analysis, the following variables were associated with $\mathrm{CV}$ risk: hypertension hazard ratio (HR): 1.69; confidence interval (CI) 95\%: 1.28-2.24, diabetes (HR: 2.67; CI 95\%: 1.98-3.61), metabolic syndrome (HR: 1.61; CI 95\%: 1.24-2.09), abdominal obesity (HR: 1.36; CI 95\%: 1.03-1.79), hypertriglyceridemia (HR: 1.67; CI 95\%: 1.22-2.30) and high triglyceride/HDL-c ratio (HR: 1.73; CI 95\%: 1.31-2.84). Hypertension, diabetes, and dyslipidemia remained associated with $\mathrm{CV}$ risk regardless of abdominal obesity.

Conclusion: In this prospective study, hypertension, diabetes, metabolic syndrome, abdominal obesity, and hypertriglyceridemia were predictors of CV risk in elderly individuals. These results confirm the relevance of controlling these CV risk factors in this age group.

Keywords: aged, cardiovascular diseases, risk factors, epidemiology

\section{Introduction}

Cardiovascular diseases (CVD) represent the main cause of mortality, morbidity, and health resource utilization in elderly individuals. ${ }^{1}$ Strategies for confronting these diseases involve the acknowledgment of factors associated with higher risk of arteriosclerotic disease and their subsequent control.

Some modifiable risk factors, such as sedentary habits, smoking, hypertension, diabetes, dyslipidemias, and obesity can be identified in the general population, all of which can be intervened upon by health care services. ${ }^{2}$ Among the elderly, even though the role of some of these factors has not been clearly defined, the effectiveness of acting on risk factors to reduce CVD has already been recognized. ${ }^{3}$

Many researchers have studied the epidemiological aspects of CVD in depth; however, the elderly are frequently excluded from such studies, particularly those who present compromised functional capacity and comorbidities. ${ }^{4}$ 
The objective of this study was to carry out a prospective analysis of the determinants of cardiovascular (CV) events among the elderly, considering the interference of several previously known factors.

\section{Methods}

\section{Design and setting}

The present research was a prospective cohort study with a 12-year follow-up period. The sample consisted of elderly outpatients (60 to 85 years old) from two geriatric clinics with similar characteristics in the city of Londrina, in southern Brazil. All patients admitted to the clinics between June 1997 and June 1998 were analyzed. The exclusion criteria were: age over 85 years, the presence of active neoplasia (except in the skin and prostate), and the inability to remain standing for the anthropometric measurements.

\section{Measurement}

The following variables were analyzed.

\section{Confounding variables}

Gender, age range (60 to 74,75 and over), regular physical activity (at least three times a week), smoking, and the presence of previous CVD (heart failure, atrial fibrillation, coronary artery disease, myocardial infarction, or stroke).

\section{Independent variables}

Hypertension: individuals were considered to have hypertension when using antihypertensive medications and/or presenting systolic blood pressure $\geq 140 \mathrm{~mm} / \mathrm{Hg}$ and diastolic blood pressure $\geq 90 \mathrm{~mm} / \mathrm{Hg}$.

Diabetes: fasting glycemia $\geq 126 \mathrm{mg} / \mathrm{dL}$ or the use of anti-diabetic medications.

\section{Pre-diabetes: fasting glycemia $\geq 100 \mathrm{mg} / \mathrm{dL}^{5}$}

Metabolic syndrome (MS): patients presenting at least three of the following disorders were considered to have MS: (1) hypertension; (2) hypertriglyceridemia ( $\geq 150 \mathrm{mg} / \mathrm{dL}$ ); (3) high density lipoprotein-cholesterol (HDL-c) $<50 \mathrm{mg} / \mathrm{dL}$ for women and $<40 \mathrm{mg} / \mathrm{dL}$ for men; (4) fasting glucose $\geq$ $100 \mathrm{mg} / \mathrm{dL}$; and (5) waist circumference $>88 \mathrm{~cm}$ for women and $>102 \mathrm{~cm}$ for men. ${ }^{6}$

Obesity and overweight: individuals whose body mass index (BMI) was $\geq 30$ and $\geq 27 \mathrm{~kg} / \mathrm{m}^{2}$, respectively.

Abdominal obesity: The waist circumference (WC) and the waist-hip ratio (WHR) were obtained and abdominal obesity was determined using the 75th percentile (differentiated by gender) as a cutoff point.
Lipids: the serum lipid levels (total cholesterol, HDL-c, and triglycerides) were obtained with the enzymatic method after a 12-hour fast. In order to calculate low-density lipoprotein (LDL-c), the Friedwald formula was used for individuals with triglycerides $<400 \mathrm{mg} / \mathrm{dL}$. Dyslipidemias were classified according to different cutoff points: total cholesterol $>200 \mathrm{mg} / \mathrm{dL}$ and $>240 \mathrm{mg} / \mathrm{dL}$; LDL-c $>100 \mathrm{mg} / \mathrm{dL}$ and $>130 \mathrm{mg} / \mathrm{dL}$; HDL-c $<40 \mathrm{mg} / \mathrm{dL}$ and $<35 \mathrm{mg} / \mathrm{dL}$; and triglycerides $>200 \mathrm{mg} / \mathrm{dL} .{ }^{7}$ A triglycerides $/ \mathrm{HDL}-\mathrm{c}$ ratio $>4$ was also analyzed as a variable related to lipid disorders. ${ }^{8}$

Dependent variable: occurrence of a fatal or non-fatal $\mathrm{CV}$ event. Patient follow up occurred every 6 months. Events were identified by the researchers' direct observation, reports by health services, or information gathered from relatives.

The CV events evaluated as outcomes were:

- CV mortality

The following deaths were considered to be of $\mathrm{CV}$ origin:

a. deaths whose underlying causes are cataloged in the tenth review of the International Classification of Diseases (ICD-10), chapter IX, codes I00 through I99, which correspond to CVDs $;{ }^{9}$

b. deaths whose underlying cause was diabetes (ICD-10, chapter IV, codes E10-E14), but the final cause of death being classified as a CVD (ICD-10 codes I00-I99);

c. sudden deaths, ie, those that occurred up to one hour after the beginning of symptoms with no evidence of other non-CV causes.

- Non-fatal events

a. Stroke-The study considered events of ischemic or hemorrhagic origin that presented neurological symptoms for at least 24 hours and were the cause of hospital admission.

b. Coronary artery disease - Patients who presented a clinical condition suggesting coronary artery disease, confirmed by at least one of the following complementary exams: exercise testing, myocardial scintigraphy, or cardiac catheterization. Patients submitted to coronary angioplasty were also considered to have coronary artery disease.

c. Myocardial infarction - Diagnosis and treatment for myocardial infarction by a medical service that included a record of hospital admission.

When more than one event happened to the same individual during the follow-up period, the first episode was considered for analysis.

\section{Statistical analysis}

The results were obtained by analyzing the Cox proportional hazard model, in which death of non-CV origin and follow- 
up loss were considered censoring. The fatal and non-fatal $\mathrm{CV}$ events observed were analyzed together as the dependent variable. Hypertension, diabetes, MS, and dyslipidemias were considered independent variables. The analysis models were adjusted for gender, age range $>75$ years, the presence of previous CVD, smoking, and regular physical activity.

The components of MS were also analyzed using a multivariate model that included statistically significant variables, such as diabetes, hypertension, abdominal obesity (WHR), and hypertriglyceridemia, in the adjusted model. The first model (A) included hypertriglyceridemia and the triglycerides/HDL-c ratio was analyzed in the second model $(\mathrm{B})$.

The significance level used was $5 \%(\alpha=0.05)$; the data were analyzed in EpiInfo 3.5.

\section{Ethical aspects}

The study was approved by the Research Ethics Committee of the Universidade Estadual de Londrina and Universidade de São Paulo and followed the Helsinki Declaration guidelines. At the initial follow up, the patients and/or their guardians were informed about the study design and signed an informed consent form.

\section{Results}

A total of 901 patients were admitted to both outpatient geriatric clinics from June 1997 to June 1998. There were 40 exclusions due to cancer diagnosis at the baseline (26 females, 14 males) and 61 because patients were older than 85 years (42 females, 19 males).

The final sample included 800 individuals aged 60 to 85 years (mean 71.2; median 70.5); 534 of whom were females $(66.8 \%)$. Thirty-one participants $(3.9 \%)$ did not complete the follow up and they were analyzed as censoring. The mean follow-up time was 11.8 years.

The total mortality during follow up was 339 (42.9\%) and 132 deaths were of CV origin (38.9\%). The following non-fatal CV events were observed: stroke (72), myocardial infarction (23), coronary artery disease (55), and recent heart failure (24). Therefore, the fatal and non-fatal events were registered as the main outcome for analysis in 233 elderly individuals (29.1\%). Table 1 presents the characteristics of the participants at the beginning of follow up.

The risk of $\mathrm{CV}$ events was statistically significant for the following variables: diabetes (HR: 2.67; CI 95\%: 1.98-3.61; $P<0.001$ ), pre-diabetes or diabetes (HR: 1.60; CI 95\%: 1.23-2.08; $P<0.001$ ), hypertension (HR: 1.69; CI 95\%: 1.28-2.24; $P<0.001$ ), MS (HR: 1.61; CI 95\%: 1.24-2.09; $P<0.001$ ), increased WHR (HR: 1.36; CI 95\%: 1.03-1.79;
Table I Baseline characteristics of the participants

\begin{tabular}{|c|c|c|c|}
\hline Characteristic & $\begin{array}{l}\text { Total } \\
(n=800)\end{array}$ & $\begin{array}{l}\text { CV events } \\
(n=233)\end{array}$ & $\begin{array}{l}\text { No CV } \\
\text { events } \\
(n=567)\end{array}$ \\
\hline Age $(y)$, mean \pm SE & $71.2(6.9)$ & $72.9(6.5)$ & $70.5(7.0)^{\ddagger}$ \\
\hline Women \% & 66.8 & 63.1 & 68.3 \\
\hline Hypertension \% & 53.9 & 67.0 & $48.5^{\ddagger}$ \\
\hline Diabetes \% & I5. I & 25.1 & $11.0^{\ddagger}$ \\
\hline CVD history \% & I7.1 & 30.5 & $12.0^{\ddagger}$ \\
\hline $\begin{array}{l}\text { Total cholesterol } \\
(\mathrm{mg} / \mathrm{dL}) \text { mean } \pm \mathrm{SE}\end{array}$ & $205.8(43.3)$ & $206.8(47.0)$ & $205.4(4 I .7)$ \\
\hline LDL-c $(\mathrm{mg} / \mathrm{dL})$ mean $\pm \mathrm{SE}$ & $126.6(37.6)$ & $126.8(38.8)$ & $126.5(37.1)$ \\
\hline $\mathrm{HDL}-\mathrm{c}(\mathrm{mg} / \mathrm{dL})$ mean $\pm \mathrm{SE}$ & $49.9(14.1)$ & $48.1(14.3)$ & $50.7(14.0)^{*}$ \\
\hline $\begin{array}{l}\text { Triglycerides }(\mathrm{mg} / \mathrm{dL}) \\
\text { mean } \pm \text { SE }\end{array}$ & | $46.5(84.0)$ & $159.2(100.5)$ & $141.2(75.5)^{\dagger}$ \\
\hline $\mathrm{BMI}\left(\mathrm{kg} / \mathrm{m}^{2}\right)$ mean $\pm \mathrm{SE}$ & $25.9(4.8)$ & $26.2(4.8)$ & $25.8(4.8)$ \\
\hline $\begin{array}{l}\text { Waist circumference } \\
(\mathrm{cm}) \text { mean } \pm \mathrm{SE}\end{array}$ & $92.2(10.8)$ & $94.1(10.9)$ & $91.4(10.7)^{\dagger}$ \\
\hline $\begin{array}{l}\text { Waist-to-hip ratio } \\
\text { mean } \pm \mathrm{SE}\end{array}$ & $0.94 \mid(0.06)$ & $0.955(0.06)$ & $0.936(0.06)^{\ddagger}$ \\
\hline Metabolic syndrome \% & 38.9 & 48.9 & $34.7^{\ddagger}$ \\
\hline Regular physical activity \% & 21.8 & 23.3 & 18.0 \\
\hline Smoking \% & 7.6 & 8.2 & 6.4 \\
\hline
\end{tabular}

Notes: $* P<0.05 ;{ }^{\dagger} P<0.01 ; \ddagger P<0.001$.

Abbreviations: CV, cardiovascular; SD, standard error; CVD, cardiovascular disease; LDL-c, low-density lipoprotein cholesterol; HDL-c, high-density lipoprotein cholesterol; BMI, body mass index.

$P<0.05$ ), hypertriglyceridemia (HR: 1.67; CI 95\%: 1.22-2.30; $P<0.01$ ), and high triglyceride/HDL-c ratio (HR: 1.73; CI 95\%: 1.31-2.84; $P<0.001$ ). No significant associations were observed for global obesity, overweight, abdominal obesity measured by WC, hypercholesterolemia, increased LDL-c, or decreased HDL-c (Table 2).

In the multivariate analysis adjusted for gender, age range, smoking, previous CVD, and regular physical activity, it was observed that hypertension $(P<0.05)$ and diabetes $(P<0.001)$ remained significantly associated with the occurrence of $\mathrm{CV}$ events. Additionally, hypertriglyceridemia model A (HR: 1.48; CI 95\%: 1.07-2.04; $P<0.05$ ) and a triglycerides/HDL-c ratio $>4-$ model B (HR: 1.56; CI 95\%: 1.17-2.08; $P<0.05$ ) also showed an independent association with $\mathrm{CV}$ risk. Abdominal obesity was not associated, regardless of the other factors, and MS was not included in the multivariate models since it presented direct collinearity with the other included factors (Table 3).

\section{Discussion}

The results reveal a particular profile of $\mathrm{CV}$ risk in this group of elderly individuals $<85$ years old. The data reinforce the role of diabetes, hypertension, MS, and abdominal obesity as determinants of $\mathrm{CV}$ risk among the elderly. In addition, among the dyslipidemias, only hypertriglyceridemia and a 
Table 2 Association between cardiovascular events and classic risk factors in older adults $(n=800)$

\begin{tabular}{|c|c|c|c|}
\hline Risk factor & $\%$ & $\begin{array}{l}\text { HR crude } \\
\text { (Cl 95\%) }\end{array}$ & $\begin{array}{l}\text { HR adjusted }{ }^{a} \\
\text { (Cl } 95 \%)\end{array}$ \\
\hline Hypertension & 53.9 & $\mathrm{I} .83(\mathrm{I} .39 ; 2.4 \mathrm{I})^{\ddagger}$ & $1.69(1.28 ; 2.24)^{\ddagger}$ \\
\hline Diabetes & 15.1 & $2.60(1.93 ; 3.50)^{\ddagger}$ & $2.67(1.98 ; 3.61)^{\ddagger}$ \\
\hline $\begin{array}{l}\text { Pre-diabetes }(\mathrm{GBL} \geq \\
100 \mathrm{mg} / \mathrm{dL}) \text { or diabetes }\end{array}$ & 33.0 & $1.74(1.34 ; 2.26)^{\ddagger}$ & $1.60(1.23 ; 2.08)^{\ddagger}$ \\
\hline Metabolic syndrome & 38.9 & $1.59(1.23 ; 2.06)^{\ddagger}$ & I.6I $(1.24 ; 2.09)^{\ddagger}$ \\
\hline Obesity $\left(\mathrm{BMI} \geq 30 \mathrm{~kg} / \mathrm{m}^{2}\right.$ ) & 18.3 & 0.99 (0.7I; I.38) & I.05 (0.75; I.47) \\
\hline $\begin{array}{l}\text { Overweight }(\mathrm{BMI} \geq \\
\left.27 \mathrm{~kg} / \mathrm{m}^{2}\right)\end{array}$ & 37.3 & $0.99(0.76 ; 1.29)$ & I.06 (0.8I; I.39) \\
\hline$W C \geq 75$ th percentile & 25.9 & 1.21 (0.9I; I.6I) & I.2I (0.91; I.62) \\
\hline $\begin{array}{l}\text { Waist-hip ratio } \geq 75 \text { th } \\
\text { percentile }\end{array}$ & 26.6 & $1.45(1.10 ; 1.91)^{\dagger}$ & $1.36(1.03 ; 1.79)^{*}$ \\
\hline $\begin{array}{l}\text { Total cholesterol }> \\
200 \mathrm{mg} / \mathrm{dL}\end{array}$ & 48.9 & $0.93(0.72 ; 1.21)$ & I. $10(0.84 ; 1.43)$ \\
\hline $\begin{array}{l}\text { Total cholesterol }> \\
240 \mathrm{mg} / \mathrm{dL}\end{array}$ & 21.5 & $1.07(0.79 ;$ I.44) & I.32 (0.97; I.79) \\
\hline LDL-c $>100 \mathrm{mg} / \mathrm{dL}$ & 69.5 & $0.83(0.63 ; 1.09)$ & $0.93(0.70 ; 1.23)$ \\
\hline $\mathrm{LDL}-\mathrm{c}>130 \mathrm{mg} / \mathrm{dL}$ & 41.3 & $1.04(0.80 ; 1.35)$ & $1.20(0.93 ; 1.57)$ \\
\hline $\mathrm{HDL}-\mathrm{c}<45 \mathrm{mg} / \mathrm{dL}$ & 34.8 & $1.36(1.05 ; 1.77)^{*}$ & $1.23(0.94 ; 1.61)$ \\
\hline $\mathrm{HDL}-\mathrm{c}<40 \mathrm{mg} / \mathrm{dL}$ & 22.8 & $1.38(1.04 ; 1.79)^{*}$ & I.27 (0.94; I.70) \\
\hline $\mathrm{HDL}-\mathrm{c}<35 \mathrm{mg} / \mathrm{dL}$ & 12.6 & $1.53(1.08 ; 2.16)^{*}$ & I.26 (0.89; I.79) \\
\hline Triglycerides $>200 \mathrm{mg} / \mathrm{dL}$ & 16.5 & $1.39(1.01 ; 1.90)^{*}$ & $1.67(1.22 ; 2.30)^{\dagger}$ \\
\hline Triglycerides/HDL-c $>4$ & 23.5 & $1.62(1.28 ; 2.13)^{\ddagger}$ & I.73 $(1.31 ; 2.84)^{\ddagger}$ \\
\hline
\end{tabular}

Notes: $* P<0.05 ; \uparrow P<0.01$; $¥ P<0.001$; ${ }^{\ddagger}$ Cox regression models adjusted for sex, age, cardiovascular disease history, regular physical activity, and smoking. Abbreviations: HR, hazard ratio; GBL, glucose blood level; BMI, body mass index; WC, waist circumference; LDL-c, low-density lipoprotein cholesterol; HDL-c, highdensity lipoprotein cholesterol.

high triglycerides/HDL-c ratio showed an association with increased $\mathrm{CV}$ risk.

Factors associated with higher $\mathrm{CV}$ risk in the bivariate analysis were still associated even after controlling for other important determinants of $\mathrm{CV}$ health, such as age, smoking, and sedentary habits. Moreover, adjustment due to the presence of previous CVD (observed in 17\% of the participants) minimized the possible influence of pathological situations diagnosed before the follow-up period.

Diabetes has been highlighted as one of the most significant factors in $\mathrm{CV}$ risk, ${ }^{4}$ and the results of the present study confirm this risk, even when individuals with glycemia $\geq 100 \mathrm{mg} / \mathrm{dL}$ were included in the risk variables. Other authors have also identified this risk pattern in different groups of elderly individuals; in a study of CVD-free elderly individuals with a 15-year follow up, diabetes and hypertension were associated with a higher risk of $\mathrm{CV}$ events. ${ }^{10}$

The risk of CV events in this study was associated with the presence of hypertension, which is consistent with another study on the elderly. ${ }^{11}$ In addition, the present prospective analysis showed that diabetes and hypertension increased
Table 3 Multivariate analysis of the risk of fatal and non-fatal cardiovascular events regarding hypertension, diabetes, abdominal obesity and hypertriglyceridemia*

\begin{tabular}{|c|c|c|c|}
\hline \multirow[t]{2}{*}{ Independent variables } & \multicolumn{3}{|c|}{$\begin{array}{l}\text { Dependent variable - } \\
\text { cardiovascular events }\end{array}$} \\
\hline & HR & $(95 \% \mathrm{Cl})$ & $P$-value \\
\hline \multicolumn{4}{|l|}{ Model A } \\
\hline Hypertension & 1.53 & $1.15-2.03$ & $<0.05$ \\
\hline Diabetes & 2.12 & $1.56-2.88$ & $<0.001$ \\
\hline WHR - percentile 75 & 1.17 & $0.89-1.55$ & ns \\
\hline Triglycerides $>200 \mathrm{mg} / \mathrm{dL}$ & 1.48 & I.07-2.04 & $<0.05$ \\
\hline \multicolumn{4}{|l|}{ Model B } \\
\hline Hypertension & 1.54 & $1.16-2.05$ & $<0.05$ \\
\hline Diabetes & 2.08 & $1.53-2.83$ & $<0.001$ \\
\hline WHR - percentile 75 & I.II & $0.84-1.48$ & ns \\
\hline Triglycerides/HDL-c $>4$ & 1.56 & $1.17-2.08$ & $<0.05$ \\
\hline
\end{tabular}

Note: *Adjusted for gender, age range $>75$ years old, smoking, previous cardiovascular disease, and regular physical activity.

Abbreviations: WHR, waist-hip ratio; HDL-c, high-density lipoprotein cholesterol; ns, non-significant.

$\mathrm{CV}$ risk regardless of the other components of MS, such as abdominal obesity and hypertriglyceridemia.

As in the general population, abdominal obesity appeared as a CV risk factor. However, in this group of elderly individuals, a statistically significant association was observed when abdominal obesity was determined by WHR and not abdominal circumference. WHR has already been indicated as a better predictor of obesity-associated risk in elderly

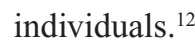

Overweight was not identified as a $\mathrm{CV}$ risk factor, even though two different levels of BMI were examined ( $\geq 27$ and $\geq 30 \mathrm{~kg} / \mathrm{m}^{2}$ ). Many authors have already demonstrated that global obesity does not represent an independent $\mathrm{CV}$ risk factor in elderly individuals. ${ }^{13,14}$ However, a study of elderly Chinese individuals found a positive association between BMI and CV risk, ${ }^{15}$ showing that BMI can still be a good CVD marker in certain ethnicities.

Furthermore, situations related to hyperglycemia, higher levels of blood pressure, and abdominal obesity were associated with higher CV risk. Thus, MS, which represents their combined expression, was also significantly associated with the analyzed outcomes. In a preliminary analysis, after five years of follow up that included only women, an association between MS and CV events was observed. ${ }^{16}$

MacNeill et al also confirmed that MS is an indicator of $\mathrm{CV}$ risk in elderly individuals, since hypertension was the component that most affected the occurrence of CVD in their follow up. ${ }^{17}$ Although there are different classifications of MS, all of them result in an evident increase of CV risk in elderly individuals. ${ }^{18,19}$ 
Hypercholesterolemia and increased LDL-c have been cited as important $\mathrm{CV}$ risk factors, and their pharmacological control represents an important tool for preventing primary or secondary $\mathrm{CV}$ disorders. However, the results of the present study did not show significant associations between high levels of total cholesterol and LDL-c and the incidence of $\mathrm{CV}$ events.

This weak association could not be the consequence of a possible smaller role of lipoproteins in the arteriosclerosis process, since this role is widely documented in the literature. Thus, it may be due to the influence of low cholesterol on mortality levels in elderly individuals, which was recently observed in the same sample. ${ }^{20}$ In this age range, low cholesterol appears to be a greater predictor of morbi-mortality than higher levels since it is frequently associated with malnutrition, fragility, and sub-clinical diseases. ${ }^{21}$

The association between hypercholesterolemia and CVD has been studied several times in the elderly, but the mechanisms to explain this association is still not clear. In a study on elderly individuals with a 13 -year follow up, higher CV risk was observed for high total cholesterol and low HDL-c. ${ }^{22}$

On the other hand, in agreement with the present findings, other authors did not identify high total cholesterol and LDL-c as CV risk factors in elderly individuals. For example, Veeranna et al did not observe an association between dyslipidemia and severity of coronary injury in elderly individuals. ${ }^{23}$ In another study with elderly diabetics, there was an association with CV risk for LDL-c and HDL-c levels in elderly individuals up to 75 years old, but the association was not significant in individuals over the age of 75 years, as was also observed in the present study. ${ }^{24}$

Our analysis possibly did not have the statistical power to identify an association between low HDL-c levels and CV risk in the adjusted analysis. A low HDL-c level is widely acknowledged as an important CV risk factor among the elderly, and a number of authors have already demonstrated this association. ${ }^{25}$

Among the dyslipidemias, hypertriglyceridemia was significantly associated with the occurrence of $\mathrm{CV}$ events, regardless of the presence of diabetes, hypertension, or abdominal obesity. Few authors have studied the independent association between triglycerides and CVD in the elderly. Mazza et al identified a high level of triglycerides as an indicator of higher $\mathrm{CV}$ risk among elderly women, although their results for men were not significant. ${ }^{26}$ Even though dealing with hypertriglyceridemia is important, it has not been fully explored by the primary and secondary prevention guidelines, ${ }^{27}$ particularly among geriatric populations.
In addition to high triglyceride levels, the ratio between serum triglycerides and HDL-c levels was also associated with higher $\mathrm{CV}$ risk. The triglyceride/HDL-c ratio indirectly reflects the levels of phenotype B low-density lipoprotein particles, which are smaller and denser. This ratio plays a fundamental role in arteriosclerosis and is associated with an important increase in CV risk.

Recognizing the triglyceride/HDL-c ratio as an independent $\mathrm{CV}$ risk factor allows the proper determination of $\mathrm{CV}$ risk by means of an inexpensive, easy, and efficient method, which has been studied by several authors. $8,26,28$

Although the results of the present study may contribute to a better understanding of the epidemiology of CVDs in the elderly, some limitations must be mentioned. The sample represents a group of elderly outpatients and was not populationbased. Nevertheless, these subjects present socio-demographic characteristics and comorbidities similar to those of the general elderly population. ${ }^{29}$ Another methodological question that could interfere in the results is that sub-clinical CV events were not identified. Their acknowledgment, even though very difficult from a methodological point of view, could have contributed to the data analysis. The outcome events were not reviewed by an independent expert committee. Lastly, this study did not consider the therapeutic regimens used to control hypertension, diabetes, and dyslipidemias, or the level of adherence to pharmacological treatment, which could have interfered with the occurrence of complications. ${ }^{30}$

As the roles of some determinants of CVD are defined, the importance of preventive measures stands out. Thus, unlike what is commonly observed, CVD prevention in older individuals should be intensified, and could generate many benefits for people in this age range as well. ${ }^{31,32}$

These results help consolidate the importance of the main $\mathrm{CV}$ risk factors in elderly populations and underscore the relevance of measures to prevent CVD and promote fewer comorbidities during the aging process.

\section{Disclosure}

The authors report no conflicts of interest in this work.

\section{References}

1. Yazdanyar A, Newman AB. The burden of cardiovascular disease in the elderly: morbidity, mortality, and costs. Clin Geriatr Med. 2009; 25(4):563-577.

2. Graham I, Atar D, Borch-Johnsen K, et al. European guidelines on cardiovascular disease prevention in clinical practice: executive summary: Fourth Joint Task Force of the European Society of Cardiology and Other Societies on Cardiovascular Disease Prevention in Clinical Practice (Constituted by representatives of nine societies and by invited experts). Eur Heart J. 2007;28(19):2375-2414. 
3. Andrawes WF, Bussy C, Belmin J. Prevention of cardiovascular events in elderly people. Drugs Aging. 2005;22(10):859-876.

4. Cigolle CT, Blaum CS, Halter JB. Diabetes and cardiovascular disease prevention in older adults. Clin Geriatr Med. 2009;25(4):607-641.

5. Ford ES, Zhao G, Li C. Pre-diabetes and the risk for cardiovascular disease: a systematic review of the evidence. J Am Coll Cardiol. 2010; 55(13):1310-1317.

6. Alberti KG, Eckel RH, Grundy SM, et al. Harmonizing the metabolic syndrome: a joint interim statement of the International Diabetes Federation Task Force on Epidemiology and Prevention; National Heart, Lung, and Blood Institute; American Heart Association; World Heart Federation; International Atherosclerosis Society; and International Association for the Study of Obesity. Circulation. 2009;120(16):1640-1645.

7. Third Report of the National Cholesterol Education Program (NCEP) Expert Panel on Detection, Evaluation, and Treatment of High Blood Cholesterol in Adults (Adult Treatment Panel III) final report. Circulation. 2002;106(25):3143-3421.

8. Bhalodkar NC, Blum S, Enas EA. Accuracy of the ratio of triglycerides to high-density lipoprotein cholesterol for predicting low-density lipoprotein cholesterol particle sizes, phenotype B, and particle concentrations among Asian Indians. Am J Cardiol. 2006;97(7):1007-1009.

9. World Health Organization. ICD-10: International statistical classification of diseases and related health problem, tenth revision. In: World Health Organization. 2nd ed. Geneve: World Health Organization; 2004.

10. Noto D, Cefalu AB, Barbagallo CM, et al. Hypertension and diabetes mellitus are associated with cardiovascular events in the elderly without cardiovascular disease. Results of a 15-year follow-up in a Mediterranean population. Nutr Metab Cardiovasc Dis. 2009;19(5):321-326.

11. Butler J, Kalogeropoulos AP, Georgiopoulou VV, et al. Systolic blood pressure and incident heart failure in the elderly. The Cardiovascular Health Study and the Health, Ageing and Body Composition Study. Heart. 2011;97(16):1304-1311.

12. Srikanthan P, Seeman TE, Karlamangla AS. Waist-hip-ratio as a predictor of all-cause mortality in high-functioning older adults. Ann Epidemiol. 2009;19(10):724-731.

13. Stephen WC, Janssen I. Sarcopenic-obesity and cardiovascular disease risk in the elderly. J Nutr Health Aging. 2009;13(5):460-466.

14. Zamboni M, Mazzali G, Zoico E, et al. Health consequences of obesity in the elderly: a review of four unresolved questions. Int J Obes (Lond). 2005;29(9):1011-1029.

15. He Y, Jiang B, Wang J, et al. BMI versus the metabolic syndrome in relation to cardiovascular risk in elderly Chinese individuals. Diabetes Care. 2007;30(8):2128-2134.

16. Cabrera MA, Gebara OC, Diament J, Nussbacher A, Rosano G, Wajngarten M. Metabolic syndrome, abdominal obesity, and cardiovascular risk in elderly women. Int J Cardiol. 2007;114(2):224-229.

17. McNeill AM, Katz R, Girman CJ, et al. Metabolic syndrome and cardiovascular disease in older people: The cardiovascular health study. J Am Geriatr Soc. 2006;54(9):1317-1324.
18. Vinluan CM, Zreikat HH, Levy JR, Cheang KI. Comparison of different metabolic syndrome definitions and risks of incident cardiovascular events in the elderly. Metabolism. 2012;61(3):302-309.

19. Wang J, Ruotsalainen S, Moilanen L, Lepisto P, Laakso M, Kuusisto J. The metabolic syndrome predicts cardiovascular mortality: a 13-year follow-up study in elderly non-diabetic Finns. Eur Heart $J$. 2007;28(7):857-864.

20. Cabrera MA, de Andrade SM, Dip RM. Lipids and all-cause mortality among older adults: a 12-year follow-up study. Scientific World Journal. 2012;2012(Article ID 930139):5p.

21. Schupf N, Costa R, Luchsinger J, Tang MX, Lee JH, Mayeux R. Relationship between plasma lipids and all-cause mortality in nondemented elderly. J Am Geriatr Soc. 2005;53(2):219-226.

22. Upmeier E, Lavonius S, Lehtonen A, Viitanen M, Isoaho H, Arve S. Serum lipids and their association with mortality in the elderly: a prospective cohort study. Aging Clin Exp Res. 2009;21(6):424-430.

23. Veeranna V, Pradhan J, Niraj A, Fakhry H, Afonso L. Traditional cardiovascular risk factors and severity of angiographic coronary artery disease in the elderly. Prev Cardiol. 2010;13(3):135-140.

24. van Hateren KJ, Landman GW, Kleefstra N, et al. The lipid profile and mortality risk in elderly type 2 diabetic patients: a ten-year follow-up study (ZODIAC-13). PLoS One. 2009;4(12):e8464.

25. Cea-Calvo L, Lozano JV, Fernandez-Perez C, et al. Prevalence of low HDL cholesterol, and relationship between serum HDL and cardiovascular disease in elderly Spanish population: the PREV-ICTUS study. Int J Clin Pract. 2009;63(1):71-81.

26. Mazza A, Tikhonoff V, Schiavon L, Casiglia E. Triglycerides + highdensity-lipoprotein-cholesterol dyslipidaemia, a coronary risk factor in elderly women: the CArdiovascular STudy in the ELderly. Intern Med J. 2005;35(10):604-610.

27. Morrison A, Hokanson JE. The independent relationship between triglycerides and coronary heart disease. Vasc Health Risk Manag. 2009;5(1):89-95.

28. da Luz PL, Cesena FH, Favarato D, Cerqueira ES. Comparison of serum lipid values in patients with coronary artery disease at $<50,50$ to 59 , 60 to 69, and $>70$ years of age. Am J Cardiol. 2005;96(12):1640-1643.

29. Freitas MP, Loyola Filho AI, Lima-Costa MF. Birth cohort differences in cardiovascular risk factors in a Brazilian population of older elderly: the Bambui Cohort Study of Aging (1997 and 2008). Cad Saude Publica. 2011;27 Suppl 3:S409-S417.

30. Iyer AS, Ahmed MI, Filippatos GS, et al. Uncontrolled hypertension and increased risk for incident heart failure in older adults with hypertension: findings from a propensity-matched prospective population study. J Am Soc Hypertens. 2010;4(1):22-31.

31. Gohlke H. Is it worth offering cardiovascular disease prevention to the elderly? Eur J Cardiovasc Prev Rehabil. 2011. Epub November 16, 2011.

32. Ligthart SA, Richard E, van Gool WA, Moll van Charante EP. Cardiovascular risk management in community-dwelling elderly: opportunities for prevention. Eur J Cardiovasc Prev Rehabil. 2011. Epub September 19, 2011.
Clinical Interventions in Aging

\section{Publish your work in this journal}

Clinical Interventions in Aging is an international, peer-reviewed journal focusing on evidence-based reports on the value or lack thereof of treatments intended to prevent or delay the onset of maladaptive correlates of aging in human beings. This journal is indexed on PubMed Central, MedLine, the American Chemical Society's 'Chemical Abstracts Ser-

\section{Dovepress}

vice' (CAS), Scopus and the Elsevier Bibliographic databases. The manuscript management system is completely online and includes a very quick and fair peer-review system, which is all easy to use. Visit $\mathrm{http}: / /$ www.dovepress.com/testimonials.php to read real quotes from published authors. 